San Jose State University

SJSU ScholarWorks

Master's Theses

Master's Theses and Graduate Research

Summer 2018

\title{
An Examination of the Demographic Antecedents and Job Outcomes of Participation in Employee Resource Groups (ERGs)
}

Emily Erin Lopez

San Jose State University

Follow this and additional works at: https://scholarworks.sjsu.edu/etd_theses

\section{Recommended Citation}

Lopez, Emily Erin, "An Examination of the Demographic Antecedents and Job Outcomes of Participation in Employee Resource Groups (ERGs)" (2018). Master's Theses. 4943.

DOI: https://doi.org/10.31979/etd.82my-hs97

https://scholarworks.sjsu.edu/etd_theses/4943

This Thesis is brought to you for free and open access by the Master's Theses and Graduate Research at SJSU ScholarWorks. It has been accepted for inclusion in Master's Theses by an authorized administrator of SJSU ScholarWorks. For more information, please contact scholarworks@sjsu.edu. 
AN EXAMINATION OF THE DEMOGRAPHIC ANTECEDENTS AND JOB OUTCOMES OF PARTICIPATION IN EMPLOYEE RESOURCE GROUPS (ERGs)

\author{
A Thesis \\ Presented to \\ The Faculty of the Department of Psychology \\ San José State University \\ In Partial Fulfillment \\ of the Requirement for the Degree \\ Master of Science
}

by

Emily Lopez

August 2018 
(C) 2018

Emily Lopez

ALL RIGHTS RESERVED 
The Designated Thesis Committee Approves the Thesis Titled

AN EXAMINATION OF THE DEMOGRAPHIC ANTECEDENTS AND JOB OUTCOMES OF PARTICIPATION IN EMPLOYEE RESOURCE GROUPS (ERGS)

by

Emily Lopez

APPROVED FOR THE DEPARTMENT OF PSYCHOLOGY

SAN JOSÉ STATE UNIVERSITY

August 2018

Altovise Rogers, Ph.D. Department of Psychology

Megumi Hosoda, Ph.D. Department of Psychology

Marie Norman Sr. Director, Talent Acquisition, Aerohive Networks 


\begin{abstract}
AN EXAMINATION OF THE DEMOGRAPHIC ANTECEDENTS AND JOB OUTCOMES OF PARTICIPATION IN EMPLOYEE RESOURCE GROUPS
\end{abstract}

\title{
By Emily Lopez
}

Employee resource groups (ERGs) are voluntary, employee-led groups formed in the workplace that focus on providing mutual support for members and that educate the organization about its members' culture, identity, or experiences. The study’s purpose was to examine demographic antecedents and job outcomes associated with ERG participation. Specifically, this study examined gender identity and professional tenure as demographic antecedents of ERG participation and the relationship between ERG participation and employee outcomes, including job embeddedness and organizational commitment. Participants included 154 individuals employed at a technology company in the Northwestern United States who completed a survey regarding their personal characteristics and participation in ERGs as well as their commitment to and embeddedness within the organization. Results showed that female employees were more likely to become members of an ERG and to participate frequently. Additionally, frequent participation in ERG activities was associated with a stronger affective bond with the organization. Results also showed that professional tenure was not related to ERG membership or frequency of ERG participation. Finally, no relationship was found between frequent ERG participation and job embeddedness. Based on the findings of study, it is recommended that ERGs are properly funded and managed to allow for consistent participation by all employees and that organizations focus on intersectionality in their promotion of ERG events. 


\section{ACKNOWLEDGEMENTS}

First, I would like to thank Dr. Altovise Rogers, Dr. Megumi Hosoda, and Dr. Howard Tokunaga for their support and contribution to my education. I feel extremely lucky to have been a part of the SJSU I/O Psychology program and it is wholly due to the passion and dedication of the faculty. You helped me push through my coursework and this thesis, but beyond that you taught me how to approach and solve complex problems. Thank you for your patience and guidance.

Next, I would like to say thank you to my parents and sisters who have politely nagged me get my thesis done. A special thank you goes to my mom who has always been an example of hard work and grit. One huge thank you to Jim who has offered me endless encouragement and support even after I ditched him for the library. You each have inspired me in different ways and I am eternally grateful.

Finally, I would like to thank Marie Norman for pushing me, giving me career advice, and taking the time to coach and develop me. Your mentorship means the world to me. Thank you! 


\section{TABLE OF CONTENTS}

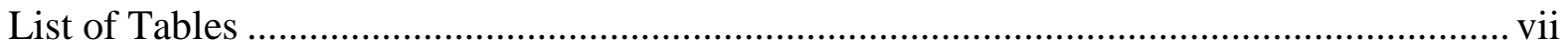

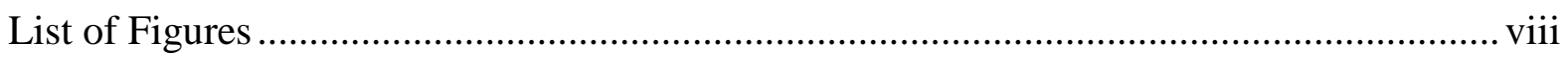

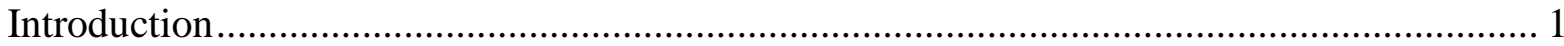

Employee Resource Group Participants ……………………………………………… 5

Employee Resource Groups and Job Outcomes ................................................................ 7

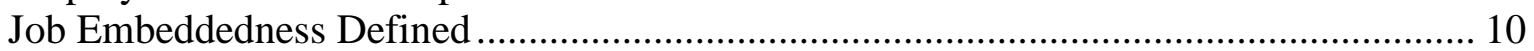

Social Identity Theory, Job Embeddedness, and Employee Resource Groups ................... 12

Organizational Commitment Defined................................................................................. 16

Social Identity Theory, Affective Commitment, and Employee Resource Groups............. 18

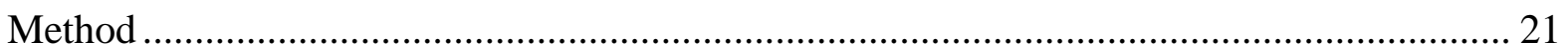

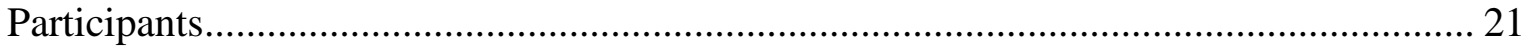

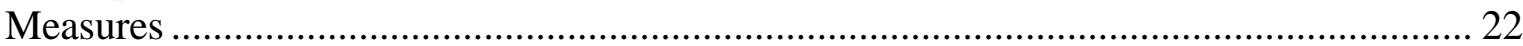

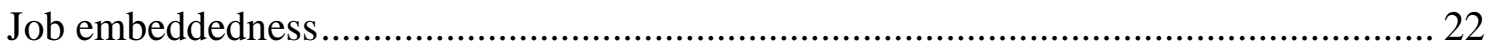

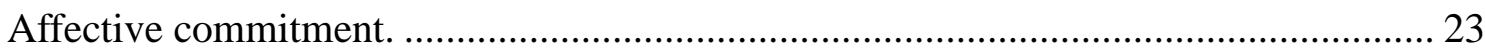

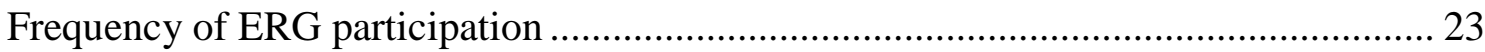

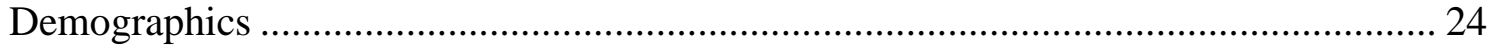

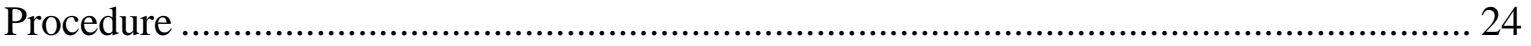

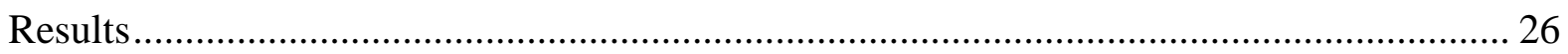

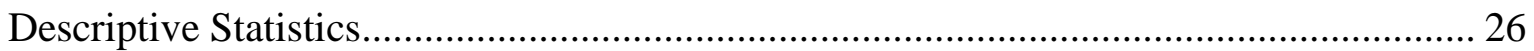

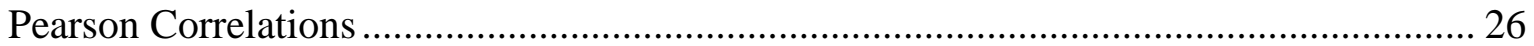

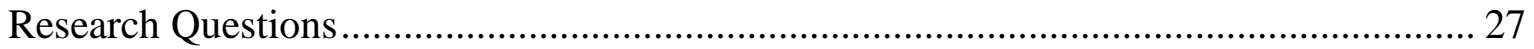

Test of Hypotheses.................................................................................................... 28

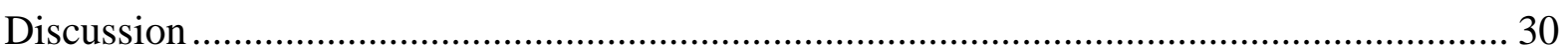

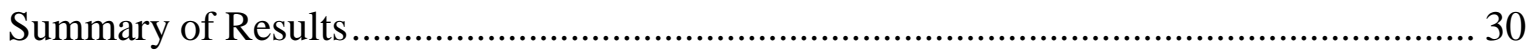

Theoretical Implications ……………………………............................................ 32

Practical Implications ............................................................................................. 33

Strengths and Limitations of the Study ........................................................................... 34

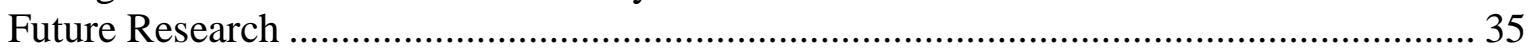

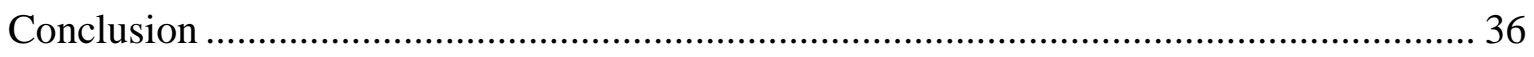

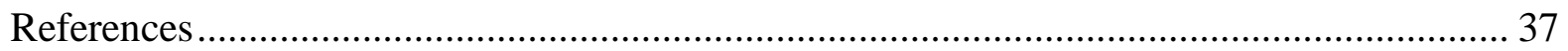

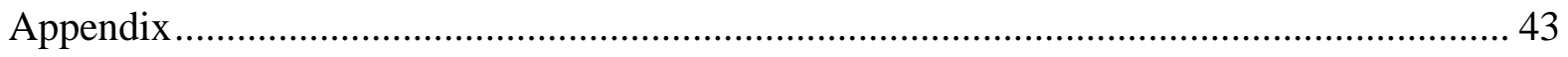

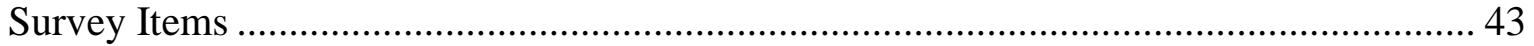




\section{LIST OF TABLES}

Table 1. Descriptive Statistics for Demographic Variables............................................... 22

Table 2. Means, Standard Deviations, Pearson Correlations, and Cronbach's Alphas.......... 26

Table 3. Chi-Square Analysis of Demographic Variables............................................... 28

Table 4. Comparing Frequent and Infrequent Participation in ERG Activities.................... 29 


\section{LIST OF FIGURES}

Figure 1. Social Identity Theory as support for the relationships between ERG participation, job embeddedness, and organizational commitment ........................................ 15 


\section{Introduction}

The current business climate is becoming increasingly globalized and diversified; hence, organizations are being forced to adapt. The demography of the United States will transform over the next several decades, and the U.S. Census (2015) predicts that by 2044, over half of all Americans will belong to a minority group. The largest increase is expected to occur in the "Two or More Races" population, followed by Asian and Hispanic populations (U.S. Census, 2015). Furthermore, many U.S. companies rely on employment-based immigration sponsorship to fill specialty occupations with foreign workers. In the 2016 fiscal year, more than 40,000 U.S. companies filed one or more H-1B visa applications (U.S. Department of Homeland Security, 2017). However, race and ethnicity are not the only means that organizations have for becoming more diverse. In 2016, women comprised nearly $47 \%$ of the U.S. civilian labor force, which is up from 29\% from the 1950s. Additionally, in 2017, the percentage of women with children under age 18 who were participating in the workforce was $70.5 \%$ (U.S. Department of Labor, 2017). This increase in diversification within organizations has precipitated a movement toward formalized diversity and inclusion programs, including employee resource groups (ERGs) (Catalyst, 2013).

ERGs are voluntary, employee-led groups that aid in fostering a diverse, inclusive workplace and are typically formed around a variety of issues, including age, ethnicity, and sexual orientation. These groups—also referred to as affinity groups, business resource groups, resource groups, and employee networks-typically align with an 
organization’s mission, values, goals, business practices, and objectives (Catalyst, 2009, 2013; Medina, 2007; Welbourne \& McLaughlin, 2013).

Employee-driven networking groups are not a new phenomenon but have undergone an evolution. During the 1960s and 1970s, these groups were born out of a demand for civil rights and the need to address discrimination (Friedman \& Deinard, 1996). They focused on "grassroots efforts to press demands on employers in concert with contentious activists in broader social movements” (Biscoe \& Safford, 2010, p. 2). In the 1990s, organizations began moving away from affirmative action plans, which were popular in decades prior, and witnessed the emergence of formal diversity and inclusion programs. Rather than merely hiring diverse employees to work for an organization, a focus was placed on ensuring that the organization did not provide any advantages or disadvantages for specific groups included in the workplace population (Thomas, 1990). This shift meant that ERGs would remain employee-driven but would become organizationally supported, with most designating an assigned executive sponsor to reinforce the company’s commitment to inclusivity (Bentley University, 2016; Biscoe \& Safford, 2010; Thomas, 1990). Increasingly, employers are requiring ERGs to establish goals and objectives tied to the organization's business objectives (Hastings, 2009).

Organizations have generally experienced a positive impact from increased diversification and the implementation of formal diversity and inclusion programs, including ERGs. Companies with more diversity in their leadership and board positions have been shown to outperform their less diverse counterparts in financial metrics, such as return on sales and return on invested capital (Catalyst, 2013). Desvaux, 
Devillard-Hoellinger, and Baumgarten (2007) found that companies in which women held three or more senior management positions scored higher on average on nine success criteria, including leadership, direction, accountability, and innovation, when compared to companies with no women in leadership positions. Companies that have implemented policies to protect the rights of the lesbian, gay, bisexual, transgender, questioning, intersex, and asexual or allied (LGBTQIA) community have been shown to have increased employee productivity and profitability (Blazovich, Cook, McDonaldHustom, \& Strawser, 2013). Additionally, organizations have self-reported that ERGs contribute to business goals (Catalyst, 2013; Mercer, 2011). MassMutual (2013) published recruitment collateral highlighting its seven ERGs, revealing that such groups have contributed to enhancing recruiting capabilities, fostering a deeper understanding of the company's customers and products, enhancing the company's brand, and growing the business in diverse markets.

Some organizations have integrated their ERGs into product testing and research. For example, Dell incorporated its NextGen ERG into testing new products based on perspectives of customers of different ages and provided feedback to the product development teams. Similarly, McDonald's engaged its Women’s Leadership Network for an evaluation of the company's menu and incorporated the group's feedback that lighter calorie options, such as salads and fresh fruit smoothies, would appeal more to women (Mercer, 2011).

As organizations continue to dedicate resources to diversity and inclusion programs and support the costs of increasing numbers of ERGs, a demand for measurable 
contributions to the business and to employees is being called for (Jackson, 2009; Welbourne \& McLaughlin, 2013). Organizations have largely measured the success of ERGs based on the number of ERGs within the organization, participation rates, and the number of activities or initiatives the ERGs host per year (Corporate Leadership Council, 2010). An opportunity exists for an examination of the outcomes of ERG membership, but very little investigation of such outcomes exists today. Although a keyword search of the subject term "diversity” yields over 40,000 peer-reviewed results in a database of academic journals, very little academic research specifically on ERGs exists. Of the articles that do explore the impact of ERGs, the focus is on the organization's business objectives rather than exploring who is likely to participate and the impact of participation in ERGs on employee outcomes and behaviors. Furthermore, to date, a limited number of academic studies exist that directly examine the relationship between participation in ERGs and individual-level job outcomes, such as organizational commitment and job embeddedness.

To address this gap in the research landscape, I crafted research questions and hypotheses in an attempt to identify factors that lead one to participate in ERGs and the outcomes of such participation. Specifically, I examined the relationship of gender identity and professional tenure with ERG membership and the frequency with which individuals participated in ERG activities. I also analyzed the relationship between frequency of ERG participation and job outcomes, including job embeddedness and organizational commitment. Job embeddedness is defined as the entirety of events and influences that make it challenging for individuals to leave an organization (Mitchell, 
Holtom, Lee, Sablynski, \& Erez, 2001), and organizational commitment is the emotional bond individuals have with an organization (Mowday, Steers, \& Porter, 1979).

The following sections contain an in-depth review of the antecedents and outcomes of ERG membership, job embeddedness, and organizational commitment. Additionally, these sections introduce social identity theory (SIT) (Tajfel, 1978) to support the argument that ERG membership relates to job embeddedness and affective commitment. Specifically, I review the constructs and dimensions of job embeddedness and highlight SIT to explain the proposed relationship between ERG membership and job embeddedness. The next section explores how outcomes of ERG membership relate to each dimension of job embeddedness. The remaining sections review the definition and components of organizational commitment as well as the outcomes and antecedents that make this construct worthy of examination. SIT will be then discussed to explain the proposed relationship between ERG membership and organizational commitment.

Finally, I explore how outcomes of ERG membership relate to affective commitment.

\section{Employee Resource Group Participants}

ERGs membership has not decreased since the 1990s, and a recent reinvigoration of these groups has produced a spike in membership. Precise membership rates are difficult to determine as organizations may define membership in different ways (Mercer, 2011). In 2011, a Senior Vice President of DiversityInc. conducted a study of what she determined to be the 50 "top diversity" companies and found that $23 \%$ of employees of those companies were members of one or more ERGs; this was up from 12\% in 2005. 
However, a survey conducted by Mercer (2011) of 15 organizations indicated participation to be much lower, at $8.5 \%$.

ERGs provide opportunities for professional development, a safe place to make a difference, and a means to learn about others from different backgrounds (Frankel, 2011; Mercer, 2011). Recent reports indicate that the most common "identities" of ERGs include women, young professionals, those of specific cultural identity (e.g., black, Latino, Asian), and LGBTQIA. Less common ERGs identities include veterans, individuals with disabilities, and parents with special needs kids (Frankel, 2011). Employees are driven to participate in ERGs for a number of reasons, including a desire for career advancement, leadership development, networking, and connections with people similar to themselves (Frankel, 2011; Mercer, 2011; Ward, 2012).

Some evidence exists regarding reasons employees participate in ERG activities, but currently, no research outlines the antecedents of ERG membership (Welbourne, Rolf, \& Schlater et al., 2015). However, some evidence exists that certain employees will frequently participate in ERG opportunities, including women and young professionals. Women and young professional ERGs are noted as two of the most common ERGs within organizations (Frankel, 2011; Kaplan, Sabin, \& Smaller-Swift, 2009). Women focused ERGs are also some of the most studied. In a conceptual paper, Welbourne, Rolf, and Schlachter (2017) conducted a literature review of academic papers that defined ERGs as formal, employee-driven groups based on a shared identity. Over half of the 29 empirical research papers identified included the study of women-based ERGs. The popularity of women-focused ERGs indicates that gender identity may factor into ERG 
participation. Furthermore, career enhancement programs, such as formal mentorship, typically involve an experienced mentor working with one or more inexperienced employees to further career ambitions or success within an organization (Haggard, Dougherty, Turban, \& Wilbanks, 2011). Given that employees use ERG activities to gain exposure to increased mentorship, leadership development, and career advancement (Catalyst, 2013; Frankel, 2001), assuming that those starting out in their career would participate in ERGs more frequently than more experienced employees is reasonable. Similarly, Friedman and Craig (2004) found that minority employees who viewed ERGs as having a large payoff in career advancement were more likely to join them. Thus, the following research questions were posited to explore the relationships among gender identity, professional tenure, and frequency of participation in ERG activities:

Research Question 1: Will gender identity be related to ERG membership?

Research Question 2: Will gender identity be related to frequency of ERG participation?

Research Question 3: Will professional tenure be related to ERG membership? Research Question 4: Will professional tenure be related to frequency of ERG participation?

\section{Employee Resource Groups and Job Outcomes}

Despite ERGs being a commonly used driver of diversity and inclusion programs, these groups are not inherently inclusive. Participation that is based on a collective identity, such as an ERG created for female employees, naturally excludes those who do not identify with that group (i.e., males). According to Kaplan et al. (2009), such 
exclusion can cause some employees to question why certain groups need an ERG and whether some groups receive preferential treatment. Organizations have begun shifting their diversity and inclusion programs to account for this. For example, many organizations now require their ERGs to accept any employee who wants to join (Kaplan et al., 2009). Deloitte, a global financial advisory firm, announced that by the end of 2018 they would eliminate all ERGs and replace them with "Inclusion Councils” in an effort to receive wider support from employees (Green, 2017). Precisely how this increased focus on inclusion will impact ERGs in the future is unclear, but organizations-including 90\% of Fortune 500 companies—are continuing to resource ERGs (Bentley University, 2016).

With membership rates and resources dedicated to ERGs continuing to grow, ample opportunity exists for empirical research in this area. However, has the research community taken notice? To date, academic research into ERGs is very limited. Welbourne et al. (2015) conducted an extensive literature review and identified only 10 papers that attempted to apply academic theory to ERGs. However, among these papers, researchers proposed a number of theoretical frameworks to apply to the study of ERGs, including cognitive dissonance theory (Festinger, 1957), negotiation and social movement theory (Scully, 2009), social ties (Friedman, Kane, \& Cornfield, 1998; Friedman \& Craig, 2004), social capital (Turner, Hogg, Oakes, Reicher, \& Wetherell, 1987), and voice/spiral of silence theory (Noelle-Neumann, 1991). Thus, currently, no overarching theory or model applied to the study of ERGs exists. However, a variety of useful articles exist that are building the research landscape on this topic (e.g., Bentley 
University, 2016; Friedman \& Deinard, 1996; Kaplan et al., 2009; Mercer, 2011;

Welbourne et al., 2015; Welbourne \& Ziskin, 2012). This study primarily uses social identity theory (SIT) (Tajfel, 1978) to support the relationship between ERG membership and job outcomes.

To date, ERG research has primarily focused on the positive benefits of membership. For example, ERGs have been shown to produce organization-level impacts on product development, brand awareness, recruiting efforts, and cultural insight (Bentley University, 2016). Kaplan et al. (2009) found that ERGs were a critical element of larger diversity programs in "creating a culture of inclusion and a workplace that supports diversity of background, thought, and perspective” (p.3).

ERGs have also had some impact on an individual level. For example, Friedman and Deinard (1996) found that participation in ERGs contributed to a positive career outlook for black managers. Additionally, Welbourne and Ziskin (2012) found that participation in ERGs created more leadership and management opportunities for minority employees. Furthermore, members of ERGs described their participation in ERGs as energizing, even though they worked extra hours (Welbourne \& Ziskin, 2012). Within the limited published academic studies identified, much of what is known about outcomes of ERG membership has been examined as a function of participation within individual ERGs and the results that the group is able to produce within the business (Welbourne et al., 2015). If leaders and organizations believe that participation in ERGs can produce positive individual-level outcomes (Bentley University, 2016; Mercer, 2011), then examining outcomes and behaviors related to participation is worthwhile. 


\section{Job Embeddedness Defined}

Voluntary turnover has been described as "the cessation of membership within an organization by an employee who received monetary compensation for participating in that organization” (Mobley, 1982, p. 68). Voluntary turnover has lasting direct costs for an organization, which can include the need to recruit for replacements, hire temporary workers, and train new staff, as well as indirect costs, such as the lowering of employee morale (Hom \& Griffeth, 1995). For these and other reasons, extensive research has been conducted on this topic (Griffeth, Hom, \& Gaertner, 2000).

Mitchell, Holtom, Lee, Sablynski, and Erez (2001) were interested in looking beyond traditional models of turnover to explore factors that influence employees to remain part of an organization. They believed that examining mechanisms that keep individuals within an organization would better inform the design of retention programs and interventions. The researchers introduced the construct of job embeddedness (JE) and defined it as the entirety of incidents, events, and influences that make it challenging for one to leave an organization. According to Zhang, Fried, and Griffeth (2012), these influences become "like a net or a web in which an individual can become stuck" (p. 1103). This construct focuses on an individual's overall perception of their embeddedness rather than on specific elements of an individual's embeddedness.

JE is a multidimensional concept that contains a two by three "matrix," including two constructs (community and organizational) and three dimensions (links, fit, and sacrifice). The first construct includes forces that keep individuals enmeshed while they are off-the-job, referred to as community JE. The second construct includes forces that 
keep individuals enmeshed while they are on-the-job, referred to as organizational JE (Mitchell et al, 2001; Wheeler, Harris, \& Sablynski, 2012). Community JE includes connections an individual has to their family, neighbors, and community. Examples of community JE include home ownership, friends living nearby, and ties to community organizations, such as neighborhood watch groups (Mitchell et al., 2001). Examples of organizational JE include connections one has with their management and colleagues or the number of work committees one is involved with (Mitchell et al., 2001).

Three dimensions of JE exist, including links, fit, and sacrifice (Mitchell et al., 2001). Links are "the extent to which people have links to other people or activities" (p. 1104). Fit is "the extent to which their jobs and communities are similar to or fit with the other aspects in their life spaces" (p. 1104). Sacrifice is "the ease with which links can be broken—what they would give up if they left, especially if they had to physically move to other cities or homes” (p. 1104). In this study, focus was on organizational JE, and, therefore, only organizational examples of links, fit, and sacrifice are provided below.

Links are connections (formal and informal) between a person and other people, groups, or organizations that are built over time and make it difficult to leave an organization (Mitchell et al., 2001; Wheeler et al., 2012). Organizational JE links include social ties to one's manager and colleagues. The more connections one has and the stronger those connections are, the more difficult it is to leave an organization (Lee, Mitchell, Sablynski, Burton, \& Holtom, 2004).

Organizational fit is the perceived compatibility an individual has with an organization, job environment, and colleagues. According to Mitchell et al. (2001), for 
fit to occur, "an employees’ personal values, career goals, and plans for the future must fit within the larger corporate culture and the demands of that person’s immediate job (knowledge, skills, abilities)" (p. 1104). The stronger the perception of fit, the more likely an individual is to become embedded within their organization (Lee et al., 2004). Sacrifice is the perceived material or psychological cost of leaving an organization (Mitchell et al., 2001). Examples of organizational sacrifice include the loss of a competitive benefits package, visibility to leadership, social ties to colleagues, or the fit one feels to the organization's mission. Sacrifice can also include the loss of anticipated benefits, such as opportunities for career advancement, stock options that have not yet vested, or a planned year-end bonus. Leaving may be more of a challenge for those who perceive they have several benefits to sacrifice in parting from the organization (Lee et al., 2004; Mitchell et al., 2001).

A number of on- and off-the-job forces exist that forge to form a "net" or "web" that embeds individuals within an organization. An individual's perception of links, fit, and sacrifice influence whether he or she will stay with an organization, and the quantity and quality of those forces determine the strength of embeddedness within an organization. Research into social identity theory (Tajfel, 1978) offers support that ERG membership relates to each dimension of JE (Douglas, 2008; Dreher \& Ash, 1990; Frankel, 2001; Milliman, Czaplewski, \& Ferguson, 2003).

\section{Social Identity Theory, Job Embeddedness, and Employee Resource Groups}

SIT (Tajfel, 1978) may provide more context regarding ERG members’ JE. SIT was created by Henri Tajfel and John Turner in an effort to explain the psychological basis of 
group behavior (Tajfel, 1978; Tajfel \& Turner, 1979, 1986). The theory assumes that individuals strive for a positive self-concept through social identity, which they gain through group membership. Furthermore, through social comparisons, people selfcategorize into group membership with others who share similar characteristics (van Dick, 2001). Tajfel and Turner $(1979,1986)$ found that even arbitrary categorization (such as group preference for abstract versus non-abstract art) was enough to produce self-esteem and positive social identity.

SIT supports ERG membership as a means of providing opportunities for employees to establish links and fit within an organization. By joining groups they identify with as psychologically relevant, individuals can form connections with their colleagues (links) and strengthen the perceived compatibility they have with those colleagues (fit). For example, in a survey, Sodexo employees reported that ERG participation strengthened interoffice relationships (Frankel, 2001).

Additionally, diversity and inclusion ERGs have been shown to encourage employees to bring their "whole selves" to work each day (Douglas, 2008) and provide a network of individuals that shares common identities, values, or career development ambitions (Welbourne et al., 2015). Thus, concluding that ERGs act as a means to establish relationships and connections and result in employees becoming more embedded through fit and links is reasonable. Specifically, ERG members create links by cultivating relationships with other members and by building relationships with leaders through the process of forming and advocating on behalf of the group. Furthermore, since ERG membership is based on identification with an identity, value, or personal goal, such as 
career development (Frankel, 2011), identification with an ERG is also assumed to increase an employee's perception of fit within the group and, by extension, of fit within the organization for supporting the group.

SIT can also support how ERG membership influences the perceived material or psychological cost of what it would take to leave an organization (sacrifice). ERGs provide network and identity categorization (Welbourne et al., 2015; Welbourne \& Ziskin, 2012), which, SIT explains, lead to self-esteem. Above and beyond the sacrifice of the direct benefits the ERG provides, one could also experience a perceived loss of self-esteem and identity gained through ERG membership if they left an organization. Moreover, ERGs provide a number of other positive benefits for the employee, including exposure and visibility to top leadership, which members would not receive in most other roles (Dreher \& Ash, 1990), increased opportunity for mentorship (Friedman et al., 1998), and leadership development (Catalyst, 2013).

In one example, employees reported achieving more promotions as a result of ERG participation (Frankel, 2001). Furthermore, Dreher and Ash (1990) found that leadership exposure and opportunities created by ERG participation became extremely valuable for members' mentoring and career development over time. Thus, it can be argued that the loss of benefits gained through ERG membership is an anticipated sacrifice that would make leaving an organization more challenging. Based on findings from previous indirect research, analyzing whether ERG participation directly relates to JE would be beneficial. As shown in Figure 1, SIT can explain the hypothesized relationship between ERG participation and JE. 
Hypothesis 1: Individuals who frequently participate in ERG activities will report higher JE than those who participate infrequently.

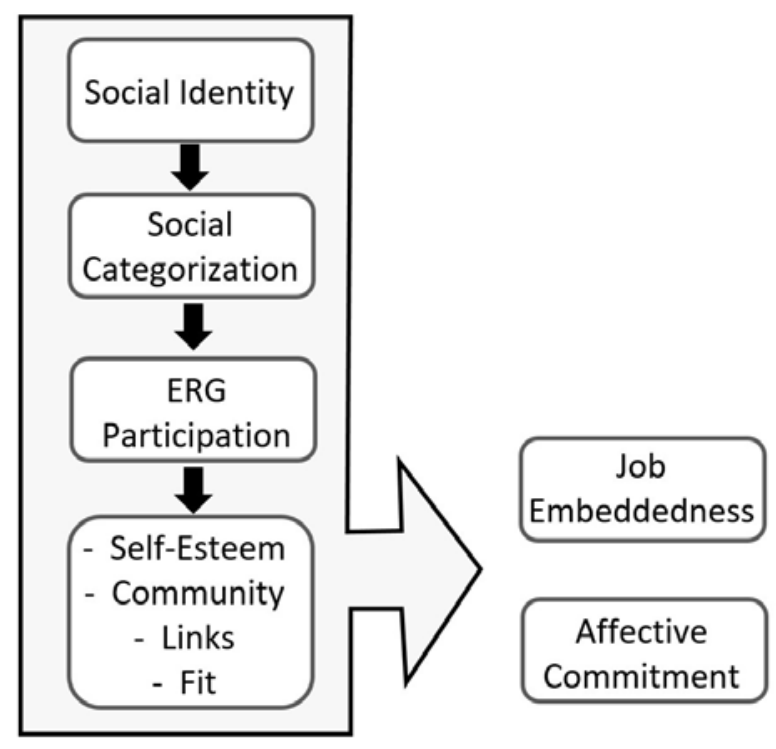

Figure 1. Social identity theory as support for the relationships between ERG participation, JE, and organizational commitment

The following sections review the definition and components of organizational commitment as well as the outcomes and antecedents that make this construct worth examining. Additionally, SIT (Tajfel, 1978) is offered as an explanation for the proposed relationship between membership in one or more ERGs and organizational commitment. Finally, this section explores how outcomes of ERG membership relate to affective commitment. 


\section{Organizational Commitment Defined}

Several definitions of organizational commitment have been proposed, and each has described the attachment of an individual to the organization. Initial research defined organizational commitment as uni-dimensional and focused primarily on affective, emotional attachment to an organization. Kanter (1968) described cohesion commitment as "the attachment of an individual's fund of affectivity and emotion to the group" (p. 507), which accounted for one’s conscious decision to remain within an organization.

Later, Mowday, Steers, and Porter (1979) developed the Organizational Commitment Questionnaire (OCQ), a 15-item scale, and defined organizational commitment as "the relative strength of an individual's identification with and involvement in a particular organization” (Mowday et al., 1979, p. 226). Their original conception of organizational commitment included acceptance of the organization's goals, a willingness to work diligently on behalf of the organization, and the desire to stay with the organization (Mowday et al., 1979). However, other researchers were interested in exploring other factors of commitment. Hrebiniak and Alutto (1972) argued that individuals calculated their attachment to the organization by determining that more gains than losses were to be found by staying. Marsh and Mannari (1977) argued that lifelong employees considered it morally correct to stay with an organization, regardless of satisfaction level or status enhancement.

Early conceptualization of organizational commitment focused on a distinction between attitudinal and behavioral commitment. Attitudinal commitment concerns the process by which individuals consider their relationship with an organization. It also 
concerns the mindset that determines how closely one's goals and values align with an organization's and, in turn, one's willingness to remain with an organization. The behavioral component focuses on the process by which individuals become locked into an organization (Mowday, Porter, \& Steers, 1982).

With the attitudinal approach, research has primarily focused on identifying antecedents of organizational commitment. Research into the behavioral approach has sought to identify conditions that lead to a continuation of the behavior of remaining part of an organization (Meyer \& Allen, 1991). Researchers began to call for a model that could better explain the facets of commitment and the attitudinal and behavioral processes by which commitment occurred (Mowday et al, 1982; Steers \& Spencer, 1977). Researchers Meyer and Allen responded to that call (Allen \& Meyer, 1990; Meyer \& Allen, 1991). They believed that separating commitment into multiple "types" would result in each type becoming mutually exclusive. Instead, the researchers argued that "it seems more reasonable to expect that an employee can experience all forms of commitment to a varying degree" (p. 68). This led them to create a model of organizational commitment that included three components that interacted to influence attitudes and work behaviors beyond just turnover (Allen \& Meyer, 1990; Meyer \& Allen, 1991). This three-component model (TCM) frames the construct as a psychological state and includes affective, normative, and continuance commitment.

Affective commitment is the emotional attachment individuals have toward an organization. Employees examine job conditions as well as congruence between their values and goals and those of an organization; the greater the identification employees 
have with an organization, the greater their willingness to remain with and exert effort on behalf of the organization (Allen \& Meyer, 1990; Meyer \& Allen, 1991; Mowday et al., 1982). Normative commitment is described as the belief that it is one's formal and informal responsibility to remain with an organization. Continuance commitment is the recognition of the costs associated with leaving an organization.

In initial evaluations of the TCM model, researchers questioned the relationships among the dimensions, specifically the degree of overlap between normative and affective commitment components (Meyer \& Allen, 1991; Mowday et al., 1982). However, additional validation research indicated that the components of the TCM model were distinguishable from one another (Meyer, Allen, \& Smith, 1993; Meyer, Stanley, Herscovitch, \& Topolnytsky, 2002). This study only focuses on affective commitment due to the stronger influence affective commitment exerts on important work attitude and behaviors (e.g., job satisfaction, job performance, job engagement) (Ko, Price, \& Mueller, 1997; McGee \& Ford, 1987; Meyer \& Allen, 1984).

\section{Social Identity Theory, Affective Commitment, and Employee Resource Groups}

Organizations expect that by providing ERGs, individuals will have dedicated avenues to be their "whole" selves while at work. In turn, this will add to the individual's commitment to and engagement with an organization (Mercer, 2011). SIT (Tajfel, 1978) may clarify this supposed relationship. As previously discussed, SIT assumes that individuals strive for a positive self-concept based on the social identity they create through group membership and that salient group identities are created when membership 
is tied to shared values or beliefs. This results in greater commitment to the group and more effort expended on behalf of the group (Hornsy \& Hog, 2000).

Direct research is limited, but some studies offer support for this idea (Hornsy \& Hog, 2000; Milliman, et al., 2003; Welbourne et al., 2015). For example, Milliman, Czaplewski, and Ferguson (2003) found that having a sense of community and shared values both had a strong positive relationship with organizational commitment. Participation in ERGs, particularly those that unite around identity, strengthen the connection and commitment of the individual to an organization (Welbourne et al., 2015). Additionally, a meta-analysis has shown that employees who experienced task variety and autonomy and who felt challenged in their role were more committed to the organization (Mathieu \& Zajac, 1990). Furthermore, task variety, autonomy, and challenge in role have been identified as outcomes of participation in ERGs (Welbourne et al., 2015; Van Aken et al., 1994). As ERGs are completely staffed by volunteers, membership allows employees to take on roles and develop skills outside their core positions (Douglas, 2008), advocate to senior leadership on behalf of the group (MacGillivray \& Golden, 2007), and act independently of their managers to accomplish goals (Welbourne et al., 2015). Finally, membership may provide access to mentorship or promotion opportunities not otherwise available (Frankel, 2001; Friedman et al., 1998).

Although a lack of direct research exists that examines the relationship between ERG membership and affective commitment, these studies support the idea that a direct examination should be conducted. As shown in Figure 1, this study aimed to examine 
whether ERG participation would be related to affective commitment and offers social identity theory to explain this relationship.

Hypothesis 2: Individuals who frequently participate in ERG activities will report higher affective commitment than those who participate infrequently. 


\section{Method}

\section{Participants}

The sample consisted of working professionals employed by a computer software company headquartered in the Northwestern region of the United States. Data were collected using an employee opinion survey. All 200 full-time employees who were members of any ERG were invited to participate. An additional random sample of 500 full-time employees who were not members of one or more ERGs were also invited to participate. Of the 700 employees invited, 187 respondents participated in the survey, reflecting an overall response rate of 26.6\%. Participants with large amounts of missing data were removed from further analyses. Thus, the final sample consisted of 154 participants.

Table 1 displays the demographic information of the sample. Participants' ages ranged from 22 to 59 years, with an average age of 32.54 years (SD = 7.33). The sample was 53.9\% $(n=83)$ male and $46.1 \%(n=71)$ female. The sample consisted of $39 \%(n=$ 60) young professionals, who had seven or fewer years of professional experience and $61 \%(n=94)$ experienced professionals, who had eight or more years of professional experience.

The sample consisted of 49.4\% $(n=76)$ ERG members and 50.6\% $(n=78)$ non-members. Participants reported their membership in ERGs as follows: 30.5\% $(n=47)$ participated in one ERG; $18.8 \%(n=29)$ participated in two or more ERGs; and 50.6\% $(n=78)$ did not participate in any ERGs. Finally, in the sample, $29.9 \%(n=46)$ 
of participants reported frequent participation in ERG activities, and 70.1\% $(n=108)$ reported infrequent participation in ERG activities.

Table 1

Descriptive Statistics for Demographic Variables

\begin{tabular}{lrr}
\hline Variable & $M$ & $S D$ \\
\hline Age & 32.54 & 7.33 \\
& $n$ & $\%$ \\
\hline Gender Identity & 71 & $46.1 \%$ \\
$\quad$ Female & 83 & $53.9 \%$ \\
$\quad$ Male & & \\
& & \\
Professional Work Experience & 60 & $39 \%$ \\
$\quad$ Young Professional (0-7 years) & 94 & $61 \%$ \\
$\quad$ Experienced Professional (8+ years) & & \\
& & \\
ERG Membership & 76 & $49.4 \%$ \\
$\quad$ Member & 78 & $50.6 \%$ \\
$\quad$ Non-member & & \\
Frequency of ERG Participation & & \\
$\quad$ Frequent & & \\
$\quad$ Infrequent & 46 & $29.9 \%$ \\
\end{tabular}

\section{Measures}

Job embeddedness. JE refers to the "combined forces that keep individuals from leaving their jobs” (Yao, Lee, Mitchell, Burton, \& Sablynski, 2004, p. 159). JE was measured using a 6-item scale called the Global Measure of Job Embeddedness Questionnaire (Crossley, Bennett, Jex, \& Burnfield, 2007). Items were responded to on a 7-point Likert scale, ranging from strongly disagree (1) to strongly agree (7), and respondents were asked to respond with their level of agreement with each statement. Some sample items of the questionnaire included: "I feel attached to this organization"; 
"It would be difficult for me to leave this organization”; “I’m too caught up in this organization to leave"; and "It would be hard for me to leave this organization." After reverse scoring one of the six items, lower scores on this scale indicated less JE, whereas higher scores indicated more JE. The internal consistency (Cronbach’s alpha) obtained for the scale was .86.

Affective commitment. Affective commitment was measured using a 6-item scale called the Affective Commitment Scale (Meyer, Allen, \& Smith, 1993). Items were responded to on a 7-point Likert scale, ranging from strongly disagree (1) to strongly agree (7), and respondents were asked to respond with their level of agreement with each statement. Sample items of the questionnaire included: "I would be very happy to spend the rest of my career with this organization”; "I enjoy discussing my organization with people outside it”; and "I really feel as if this organization's problems are my own.” After reverse-scoring three of the six items, lower scores on this scale indicated less organizational commitment, whereas higher scores indicated more JE. The internal consistency (Cronbach’s alpha) obtained for the scale was .70.

Frequency of ERG participation. Frequency of ERG participation refers to the self-report measure of how frequently one participates in activities hosted by various ERGs within one's organization. A single item was included to measure participation frequency: "How frequently do you participate in ERG activities?” Responses to the item were collected on a 7-point Likert frequency scale and included: never (1), almost never (2), occasionally (3), sometimes (4), frequently (5), almost always (6), and always (7). Frequency of ERG participation was transformed into a categorical variable in order 
to examine group differences between who were "frequent" and "infrequent” participants in ERG activities. For purposes of the transformation, participants with responses of never, almost never, and occasionally were classified as "infrequent," whereas responses of sometimes, frequently, almost always, and always were classified as "frequent."

Demographics. Participants were asked to answer four questions related to their demography, including gender identity, professional work experience, membership status in ERGs, and frequency of participation in ERG activities.

\section{Procedure}

An online survey hosted on Qualtrics ${ }^{\circledR}$ was used to collect data. The survey link, a description of the survey, a reminder of the confidentiality of survey responses, and the informed consent were sent to participants via email. The email also contained instructions for entering a raffle for a $\$ 200$ prize. Any individual with access to the email was instructed that participation in the survey was not required to participate in the raffle. By clicking the survey link in the email, participants were automatically redirected to Qualtrics, where no login credentials were required to access the survey. Individuals who clicked on the survey link were again presented with the informed consent form and a reminder of the confidentiality of their responses. Participants who agreed to the informed consent were instructed to click "continue,” where they were presented with the survey items. Individuals who did not agree to the informed consent were instructed to exit the survey by closing the web browser. Participants filled out the survey as well as the demographic information about themselves. The administrating site stored all results. Participants who completed the survey to its conclusion were presented with a final 
browser window that included text thanking them for their time, and they were again provided instructions for entry into the raffle.

\section{Statistical Analysis}

The descriptive statistics included the means and standard deviations of the measured variables. I ran Pearson correlations to examine the relationships between the measures. Next, chi-square tests of independence were computed to look for the relationships in the categorical variables proposed in the research questions and to test how likely it was that the observed distributions were due to chance. Finally, the two hypotheses were tested using independent sample t-tests to look for significant differences in the population means. All statistical analyses were conducted using the IBM SPSS v. 24 software package. 


\section{Results}

\section{Descriptive Statistics}

Table 2 displays the means, standard deviations, Pearson correlations among the measured variables, and Cronbach’s alphas for these variables. Participants reported moderate levels of JE $(M=4.49, S D=1.06)$ and affective commitment $(M=4.80$, $S D=0.87)$. These results indicated the typical respondent was moderately embedded in his or her organization and had a modest, though not strong, bond with the organization.

Generally, participants reported low ERG participation, with 70.1\% $(n=108)$ reporting infrequent participation and only 29\% $(n=46)$ reporting frequent participation. ERG members $(84.8 \%, n=39)$ were the vast majority of frequent ERG participants compared to those who were not ERG members $(15.2 \%, n=7)$. The majority of infrequent participants included non-members $(65.7 \%, n=71)$, but ERG members who participated infrequently were also included $(34.3 \%, n=37)$.

Table 2

Means, Standard Deviations, Pearson Correlations, and Cronbach's Alphas

\begin{tabular}{lccccc}
\hline Measure & $M$ & $S D$ & 1 & 2 & 3 \\
\hline JE & 4.49 & 1.06 & $(.86)$ & & \\
Affective Commitment & 4.80 & 0.87 & $.73^{* * *}$ & $(.70)$ & \\
$\begin{array}{l}\text { Frequency of ERG } \\
\text { Participation }\end{array}$ & $\begin{array}{c}\text { Infrequent (70.1\%) } \\
\text { Frequent (29.9\%) }\end{array}$ & 0.46 & .14 & $.16^{*}$ & - \\
\hline Note. ${ }^{*} p<.05 . * * p<.01 . * * * p<.001$. & & & & \\
\hline
\end{tabular}
in parenthesis on the diagonal.

\section{Pearson Correlations}

As shown in Table 2, the strongest correlation found was between JE and affective organizational commitment $(r=.73 p<.001)$. This strong positive relationship indicated 
that employees who were embedded within the organization also had a strong bond with the organization. No significant relationship was found between frequency of ERG participation and JE ( $r=.14, p=.09)$; however, a weak positive correlation was found between frequency of ERG participation and affective commitment ( $r=.16, p=.04)$. This relationship indicated that employees who participated frequently in ERG activities also had a strong bond with the organization.

\section{Research Questions}

Table 3 represents the results of the chi-square tests of independence. Research Question 1 examined whether gender identity would be related to ERG membership. A significant relationship was found $\chi^{2}(1, N=154)=5.07, p=.02$. Results showed that women were more likely to be members of an ERG than men. Similarly, men were more likely to be non-ERG members. Research Question 2 investigated whether gender identity would be related to frequency of ERG participation. A significant relationship was found $\chi^{2}(1, N=154)=7.58, p=.01$. Results showed that women were more likely than men to be frequent participants of ERG activities, and men were more likely to be infrequent ERG participants than women. Research Question 3 examined whether professional tenure would be related to ERG membership. It was indicated that the

percentage of ERG members did not differ by professional tenure $\chi^{2}(1, N=154)=0.63$, $p=.43$ ). Finally, Research Question 4 investigated whether professional tenure was related to frequency of ERG participation, and no significant relationship was found $\left.\chi^{2}(1, N=154)=2.17, p=.14\right)$. The percentage of participants who frequently participated in ERG activities did not differ by professional tenure. Overall, the 
chi-square tests of independence revealed that gender identity was related to ERG membership and frequency of ERG participation, but professional tenure was not.

Table 3

Results of Two-way Chi-Square Analyses

\begin{tabular}{lcccc}
\hline Group & \multicolumn{2}{c}{$\mathrm{n}(\%)$} & $\chi^{2}$ & $p$ \\
\hline Research Question 1 & $\underline{\text { ERG Member }}$ & $\frac{\text { Non-ERG }}{\text { Member }}$ & $5.07^{\mathrm{a}}$ & $.02 *$ \\
& $n=42(59.2 \%)$ & $n=\underline{29(40.8 \%)}$ & & \\
Female & $n=34(41 \%)$ & $n=49(59 \%)$ & & \\
Male & &
\end{tabular}

Research Question 2

Female

Male

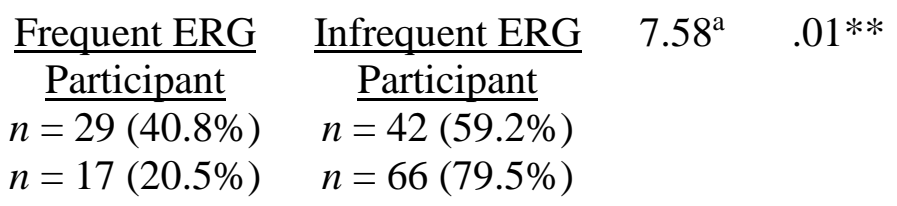

Research Question 3

$\begin{array}{lccc} & \text { ERG Member } & \frac{\text { Non-ERG }}{\text { Member }} & 0.63^{\mathrm{a}} \\ \text { Young Professional } & n=32(53.3 \%) & n=28(46.7 \%) \\ \text { Experienced Professional } & n=44(46.8 \%) & n=50(53.2 \%)\end{array}$

Research Question 4

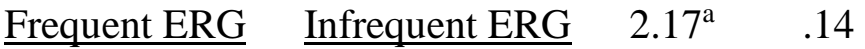

Young Professional Participant $\quad$ Participant

Experienced Professional $n=24(25.5 \%) \quad n=70(74.5 \%)$

Note. ${ }^{\text {a }} \mathrm{df}=1$

$* p<.05 .{ }^{* *} p<.01$.

\section{Test of Hypotheses}

Hypothesis 1 stated that individuals who frequently participated in ERG activities would report higher JE than those who participated infrequently. Although those who frequently participated in ERGs had higher JE $(\mathrm{M}=4.72, \mathrm{SD}=1.02)$ compared to those who infrequently participated in ERGs $(M=4.40, \mathrm{SD}=1.07)$, results showed no 
significant difference in JE resulting from frequency of ERG participation

$(t(152)=-1.73, p=.09)$. Thus, Hypothesis 1 was not supported.

Table 4

Comparing Frequent and Infrequent Participation in ERG Activities on JE and Affective Commitment

\begin{tabular}{lccccc}
\hline \multicolumn{1}{c}{ Variable } & \multicolumn{5}{c}{$\begin{array}{c}\text { Frequency of } \\
\text { ERG participation }\end{array}$} \\
\hline \multirow{3}{*}{$\mathrm{JE}$} & & $\frac{\text { Frequent }}{(n=46)}$ & $\frac{\text { Infrequent }}{(n=108)}$ & $t$ & $p$ \\
& $M$ & 4.72 & 4.40 & -1.73 & .09 \\
\multirow{2}{*}{ Affective Commitment } & $S D$ & 1.02 & 1.07 & & \\
& $M$ & 5.02 & 4.71 & -2.16 & $.04 *$ \\
& $S D$ & 0.77 & 0.90 & & \\
\hline
\end{tabular}

Note. $* p<.05$.

Hypothesis 2 stated that individuals who frequently participate in ERG activities would report higher affective commitment than those who infrequently participated. Results showed a significant effect of frequency of ERG participation on affective commitment $(t(152)=-2.03, p=.04)$ such that those who frequently participated in ERG activities ( $\mathrm{M}=5.02, \mathrm{SD}=.08)$ reporting significantly higher affective commitment compared to those who infrequently participated $(\mathrm{M}=4.71, \mathrm{SD}=.09)$. These results supported Hypothesis 2. 


\section{Discussion}

\section{Summary of Results}

This study’s purpose was to explore demographic antecedents and individual-level job outcomes associated with ERG participation. Specifically, this study examined gender identity and professional tenure as demographic antecedents of ERG participation and tested the relationships among ERG participation, and JE and affective commitment as job outcomes of ERG participation. Given the limited research on ERGs, opportunity existed for this examination to provide valuable insight into organizations with a focus on diversity and inclusion.

Research Questions 1 and 2 examined whether gender identity would be related to ERG membership and frequency of participation in ERG activities, respectively. Results showed that gender identity was related to both ERG membership and frequency of ERG participation, such that more women joined an ERG and to frequently participate in ERG activities than men. Alternatively, more men were non-ERG members and did not participate in ERG activities compared to women. These results are consistent with previous research, which shows that female-focused ERGs are one of the most common identity-based ERGs (Frankel, 2011), and, thus, women have more opportunity to join an ERG and participate in events hosted by an ERG.

Research Questions 3 and 4 investigated whether professional tenure would be related to ERG membership and frequency of participation in ERGs, respectively. Results did not show a relationship between tenure and ERG membership or frequency of ERG

participation. This suggests that the amount of professional experience that individuals 
had did not influence whether they sought out opportunities offered by ERG participation. No direct research has linked professional tenure to ERG participation; however, this result is inconsistent with research that has shown that young professionals' ERGs are among the most common (Frankel, 2011) and that members seek out ERG participation as a means of professional development and career advancement (Frankel, 2011; Mercer, 2011; Ward, 2012). This finding could be the result of employees joining these groups to enhance their social identity and expand their network rather than for professional development. This result could be due to the existence of development or promotion programs outside of ERGs that might reduce their appeal as a vehicle for young professionals to advance their career in the organization. Such programs include mentorship, rotational leadership, and development opportunities through an organization's social impact department. However, this interpretation is speculative; thus it should be interpreted with caution.

In sum, results of the present study demonstrated that gender identity was shown to be a demographic antecedent of ERG membership and frequency of ERG participation, but professional tenure was not. Given the limited research on ERGs, ample opportunity exists for further exploration of the antecedents of ERG membership and participation.

Hypothesis 1 stated that individuals who frequently participated in ERG activities would report higher JE than those who participated infrequently. Results did not support this hypothesis as no significant difference was found in JE between frequent and infrequent participants in ERG activities. This result could still be explained by social identity theory (Tajfel, 1972). A key component of social identity is psychologically 
relevant attachment to the group, and thus, the ERGs that employees participated in might not have been particularly psychologically relevant to them. Unfortunately, type of ERG participated in, strength of identification with one's ERG, and satisfaction with one's ERG were not examined in this study. Thus, this suggestion is speculative and warrants further research.

Hypothesis 2 stated that individuals who frequently participated in ERG activities would report higher affective commitment than those who participated infrequently. Results supported this hypothesis, such that frequent participants in ERG activities reported higher affective commitment than infrequent participants. This finding is consistent with those of Milliman et al. (2003) who found that a sense of community had a positive relationship with affective commitment. The results can be explained by social identity theory (Tajfel, 1972), which proposes that individuals strive for a positive self-concept based on the social identity they create through group membership and that salient group identities form when membership is tied to shared values or beliefs. This suggests that relationships built through ERG memberships increase commitment to an organization (Hornsy \& Hog, 2000). Finally, given that an organization supports and funds the ERGs, employees may feel that the organization supports the ERG's purpose and cares about them. Thus, it follows that they would become more committed to the organization.

\section{Theoretical Implications}

This study found a significant relationship between ERG participation and affective commitment. This implies that participation in ERG activities creates a sense of 
community and reinforces shared values between the participant and the organization. This provides support for previous literature that suggests that participation in ERGs, particularly those that unite around identity, will strengthen the connection and commitment of the individual to the organization (Welbourne et al., 2015). Additionally, the results of the study add to the ERG literature as it was the first study to examine the relationship between ERG participation and JE. Finally, as currently no overarching theory or model applied to the study of ERGs exists (Bentley University, 2016; Friedman \& Deinard, 1996; Kaplan et al., 2009; Mercer, 2011; Welbourne, Rolf, \& Schlachter, 2015; Welbourne \& Ziskin, 2012), this study considered social identity theory as a recommended framework.

\section{Practical Implications}

Based on the finding that frequent participation in ERG activities influenced one's affective commitment, I recommend that ERGs are properly funded and managed to allow for consistent participation in ERG initiatives or events. Furthermore, based on the finding that was low participation in ERG activities exists regardless of membership status, I recommend that organizations focus on intersectionality-the interconnection of social categorizations, such as race and gender identity that apply to a group or individual —in their marketing of ERG programming. For example, ERGs that focus on a single identity (i.e., LatinX) could lead employees to opt out of such groups by questioning whether the events were intended for them or only for individuals who strongly identify with the group. This could indicate that employees do not feel welcome to participate in activities if they do not identify strongly with a group. I recommend that 
the organizations create policies that clarify that anyone is welcome to join any ERG and that membership is not required to participate in ERG activities. Similarly, marketing and notification of ERG opportunities should be shared with all employees.

\section{Strengths and Limitations of the Study}

One strength of this study was the unique addition it made to the ERG literature as academic research on ERGs is limited (Welbourne et al., 2017). This study was the first to examine differences in JE and organization commitment based on frequency of ERG

participation. Furthermore, this study examined outcomes of ERG participation across a number of different identity-based ERGs rather than studying participants of an individual identity-based ERG. However, this study had design limitations that needs to be addressed. First, limitations existed as to the sample, demographics, and constructs collected. Participants worked for a single organization and were more experienced in their careers, which may have impacted the examination of the influence of professional tenure on ERG participation. Future research could collect data from a wide cross-section of industries and professional tenure. Additionally, this study did not control for the type of ERG participated in, tenure with the current organization, tenure within ERGs, or satisfaction with one's ERG. Because each of these variables directly relates to how psychologically relevant the group becomes to an individual, the lack of one or more of these controls may have led to the lack of the significant relationship between ERG participation and JE.

Another limitation of the study is related to the scales used to measure JE and affective commitment. The JE scale was adapted from previous research and was a 
6-item scale that did not include subscales to measure each dimension of JE. Thus, I was not able to conduct an examination of each subscale of the dimensions of JE. Future research could explore the relationship of ERG participation with links, fit, and sacrifice individually to gain a more complete understanding of these relationships.

The final limitation of this study was the data measurement design. I intended to explain the differences between individuals who participated in ERGs and those who did not. Thus, categorical variables were used to explore ERG membership and frequency of ERG participation. This design allowed me to compare these groups, but a limitation was found in terms of our ability to differentiate between degrees of participation frequency. This might have led me to overlook variability within each group (e.g., frequent participation, infrequent participation), which could have resulted in the lack of the significant relationship between ERG participation frequency and JE.

\section{Future Research}

As research on ERGs is still very limited, more research should be conducted to explore the antecedents and outcomes of participation in these groups. Additionally, further research to support social identity theory as a framework to inform ERG research is warranted. Exploring whether ERG members report stronger identification with an organization than non-members would be interesting. Additionally, investigating whether that identification with an organization moderates the relationship between ERG participation and individual-level outcomes, such as organizational commitment, would be interesting. Given the results of this study, which showed that nearly $10 \%$ of frequent participants in ERG activities report themselves as non-members, examining whether a 
relationship exists between ERG participation and job outcomes, regardless of ERG member status, would be worthwhile. Finally, because companies with diversity in executive and board positions outperform companies lacking diversity in financial metrics (Catalyst, 2013; Desvaux et al., 2007), examining whether ERGs impact company performance would be worthwhile. Similarly, I recommended an examination to determine whether companies with ERGs outperform similar companies that lack ERGs in measures of inclusion or organizational support.

\section{Conclusion}

ERGs have existed since the 1970s and are seemingly here to stay. The prevalence of ERGs in organizations is increasing; however, academic study of these unique groups is largely absent. This study’s purpose was to explore gender identity and professional tenure as demographic antecedents of ERG participation and to test the relationships among ERG participation, JE, and organizational commitment as job outcomes. Results demonstrated, gender identity was found to be related to ERG membership and participation, but professional tenure was not. This study has provided support for the need for further examination of the antecedents of ERG participation. Frequency of ERG

participation was not found to be related to JE. However, frequency of ERG participation was found to be related to organizational commitment. These findings have important theoretical and practical implications in that participation in ERG activities influences job outcomes, and further studies should be conducted to explore those outcomes. Furthermore, the results of this study highlight the importance of promoting intersectionality in ERG membership, communications, and events. 


\section{References}

Allen, N. J., \& Meyer, J. P. (1990). The measurement and antecedents of affective, continuance, and normative commitment to the organization. Journal of Occupational Psychology, 63, 1-18. Retrieved from https://www.researchgate. net/file.PostFileLoader.html?id=56f9cc985b4952105156b3c0\&assetKey=AS:344 771819261952@1459211416328

Bentley University. (2016). Employee resource groups [White paper]. Retrieved September 8, 2017, from https://www.bentley.edu/files/2017/03/17/ Bentley \%20CWB\%20ERG\%20Research\%20Report\%20Fall\%202016.pdf

Biscoe, F., \& Safford, S. (2010). Employee affinity groups: Their evolution from social movement vehicles to employer strategies. Perspectives on Work, 14, 42-45. Retrieved from https://hal-sciencespo.archives-ouvertes.fr/hal-1052900/document

Blazovich, L.J., Cook, K., McDonald-Hustom, J., \& Strawser, W. (2013). Do gayfriendly corporate policies enhance firm performance? SSRN Electronic Journal, doi: $10.2139 /$ ssrn.2243189.

Catalyst. (2009). The catalyst guide to employee resource groups [White paper]. Retrieved September 8, 2017, from http://www.catalyst.org/system/files/erg1crossreference.pdf

Catalyst. (2013). Why diversity matters [White paper]. Retrieved September 8, 2017, from http://www.catalyst.org/system/files/why_diversity_matters_catalyst_0.pdf

Corporate Leadership Council. (2010). Developing a diversity strategy [Webinar]. Retrieved from https://www.cebglobal.com/human-resources/diversityinclusion.html?referrerTitle=Diversity\%20\%26\%20Inclusion\&referrerContentTy $\mathrm{pe}=$ indexpage\&referrerURL=http\%3A\%2F\%2Fwww.cebglobal.com\%2Fhumanresources\%2Fdiversity-inclusion\%2Fdiversity-and-inclusion.html\&referrer ComponentName=Breadcrumb\&pageRequestId=0eec5010-a5bf-4e6d-8ad057635a5b6a0f

Desvaux, G., Devillard-Hoellinger, S., and Baumgarten, P. (2007). Women matter: Gender diversity, a corporate performance driver [White paper]. McKinsey, Retrieved September 8, 2017, from https://www.mckinsey.de/files/Women _Matter_1_brochure.pdf

Douglas, P. H. (2008). Affinity groups: Catalyst for inclusive organizations. Employment Relations Today, 34(4), 11-18. Retrieved from http://onlinelibrary.wiley.com/doi/ 10.1002/ert.20171/pdf 
Dreher, G. F., \& Ash, R. A. (1990). A comparative study of mentoring among men and women in managerial, professional, and technical positions. Journal of Applied Psychology, 75, 539-546. doi: 10.1037/0021-9010.75.5.539

Festinger, L. (1957). A theory of cognitive dissonance. Stanford, CA: Stanford University Press.

Frankel, D. (2011). Employee-resource groups webinar [Webinar]. DiversityInc. Retrieved from diversityinc.com\%2Fwebinar_series\%2FFeb282012DiversityInc Webinar\%2Fpresentation.pdf\&usg=AOvVaw0_yzQ3KNkrehJk91pnHOB5

Friedman, R. A., \& Craig, K. M. (2004). Predicting joining and participating in minority employee network groups. Industrial Relations, 43, 793-816. doi: $10.1111 / \mathrm{j} .0019-8676.2004 .00362 . \mathrm{x}$

Friedman, R. A., \& Deinard, C. (1996). "Black caucus groups at Xerox Corporation," in managerial excellence through diversity. M. Gentile (Eds.), Text and cases, (pp. 300-313. Chicago: Irwin.

Friedman, R.A., \& Holtom, B. (2002). The effects of resource groups on minority employee turnover intention. Human Resource Management, 41, 405-421. doi: 10.1002/hrm.10051

Friedman, R. A., Kane, M., \& Cornfield, D. B. (1998). Social support and career optimism: Examining the effectiveness of network groups among black managers. Human Relations, 51, 1155-1177. doi: 10.1023/A:1016973611184

Green, J. (2017, July). Deloitte thinks diversity groups are passé. Bloomberg Businessweek. Retrieved from https://www.bloomberg.com/news/articles/201707-19/deloitte-thinks-diversity-groups-are-pass

Griffeth, R. W., Hom, P. W., \& Gaertner, S. (2000). A meta-analysis of antecedent and correlates of employee turnover: Update, moderator tests, and research implications for the next millennium. Journal of Management, 26, 463-488. doi: $10.1177 / 014920630002600305$

Haggard, D.L., Dougherty, T., Turban, D.B., \& Wilbanks, J.E. (2011). Who is a mentor? A review of evolving definitions and implications for research. Journal of Management, 37, 280-304. doi: 10.1177/0149206310386227

Hastings, R. (2009). Employee resource groups can create labor issues. SHRM. Retrieved from http://www.shrm.org/hrdisciplines/Diversity/Articles/Pages/ ERGsLaborIssues.aspx 
Hrebiniak, L.G., \& Alutto, J.A. (1972). Personal and role-related factors in the development of organizational commitment. Administrative Science Quarterly, 17, 555-557. doi: $10.2307 / 2393833$

Hom, P. W., \& Griffeth, R. W. (1995). Employee turnover. Cincinnati, OH: South/Western

Hornsey, M. J., \& Hogg, M. A. (2000). Assimilation and diversity: An integrative model of subgroup relations. Personality and Social Psychology Review, 4, 143-156. doi: 10.1207/S15327957PSPR0402_03

Jackson, T. (2009). Igniting the power of employee resource groups. Profiles in Diversity Journal, 11, 41.

Kanter, R. M. (1968). Commitment and social organization: A study of commitment mechanisms in utopian communities. American Sociological Review, 33, 499517. doi: $10.2307 / 2092438$

Kaplan, M.M., Sabin, E., \& Smaller-Swift, S. (2009). The Catalyst guide to employee resource groups. Volume 1: Introduction to ERGS [White paper]. Retrieved September 8, 2017, from http://www.catalyst.org/knowledge/catalyst-guideemployee-resource-groups-1-introduction-ergs

Ko, J. W., Price, J. L., \& Mueller, C. W. (1997). Assessment of Meyer and Allen’s three component model of organizational commitment in South Korea. Journal of Applied Psychology, 82, 961-973

Lee, T. W., Mitchell, T. R., Sablynski, C. J., Burton, J. P., \& Holtom, B. C. (2004). The effects of job embeddedness on organizational citizenship, job performance, volitional absences, and voluntary turnover. Academy of Management Journal, 47, 711-722. doi: 10.2307/20159613

MacGillivray, E. D., \& Golden, D. (2007). Global diversity: Managing and leveraging diversity in a global workforce. International HR Journal, 38-46. Retrieved from https://pdfs.semanticscholar.org/ab8f/acdccb1aa3dc816438ca2070ed93a5ef8fa3.p df

Marsh, R. M., \& Mannari, H. (1977). Organizational commitment and turnover: A predictive study. Administrative Science Quarterly, 22, 57-75. doi: $10.2307 / 2391746$

MassMutual. (2013). 2012 Diversity \& Inclusion Report [White paper]. Retrieved September 8, 2017, from https://www.massmutual.com/mmfg/pdf/ 2012 \%20Diversity\%20\&\%20Inclusion\%20Report.pdf 
Mathieu, J. E., \& Zajac, D. M. (1990). A review and meta-analysis of the antecedents, correlates, and consequences of organizational commitment. Psychological Bulletin, 108, 171-194. doi: 10.1037/0033-2909.108.2.171

McGee, G. W., \& Ford, R. C. (1987). Two (or more?) dimensions of organizational commitment: Reexamination of the affective and continuance commitment scales. Journal of Applied Psychology, 72, 638-642.

Medina, H. (2007). Some companies developing affinity for employee groups. Hispanic Business, 29, 86-87.

Mercer. (2011). ERGs come of age: The evolution of employee resource groups [White paper]. Retrieved September 8, 2017, from http://docplayer.net/5069891-Ergscome-of-age-the-evolution-of-employee-resource-groups.html

Meyer, J. P., \& Allen, N. J. (1991). A three-component conceptualization of organizational commitment. Human Resource Management Review, 1, 61-89. doi: 10.1016/1053-4822(91)90011-Z

Meyer, J. P., Allen, N. J., \& Smith, C. A. (1993). Commitment to organizations and occupations: Extension and test of a three-component conceptualization. Journal of Applied Psychology, 78, 538-551. doi: 10.1037/0021-9010.78.4.538

Meyer, J.P., Stanley, D.J., Herscovitch, L., \& Topolnytsky, L. (2002). Affective, continuance, and normative commitment to the organization: A meta-analysis of antecedents, correlates, and consequences. Journal of Vocational Behavior, 61, 20-52. doi:10.1006/jvbe.2001.1842

Milliman, J., Czaplewski, A. J., \& Ferguson, J. (2003). Workplace spirituality and employee work attitudes: An exploratory empirical assessment. Journal of Organizational Change Management, 16, 426-47. doi.org/10.1108/095348 10310484172

Mitchell, T. R., Holtom, B. C., Lee, T. W., Sablynski, C. J., \& Erez, M. (2001). Why people stay: Using job embeddedness to predict voluntary turnover. Academy of Management Journal, 44, 1102-1121. doi: 10.2307/3069391

Mobley, W. H. (1982). Employee turnover: Causes, consequences, and control. Reading, Mass.: Addition-Wesley.

Mowday, R. T., Porter, L. W., \& Steers, R. M. (1982). Employee-organization linkages: The psychology of commitment, absenteeism and turnover. New York: Academic Press. 
Mowday, R.T., Steers, R.M., \& Porter, L.W. (1979). The measurement of organizational commitment. Journal of Vocational Behavior, 14, 224-247. doi: 10.1016/00018791(79)90072-1

Noelle-Neumann, E. (1991). The theory of public opinion: The concept of the spiral of silence. Annals of the International Communication Association, 14, 256-287. doi: 10.1080/23808985.1991.11678790

Scully, M. A. (2009). A rainbow coalition or separate wavelengths? Negotiations among employee network groups. Negotiation and Conflict Management Research, 2, 74-91. doi: 10.1111/j.1750-4716.2008.00029.x

Steers, R. M., \& Spencer, D. G. (1977). The role of achievement motivation in job design. Journal of Applied Psychology, 62, 472-479. doi: 10.1037/00219010.62.4.472

Tajfel, H. (1978). Social categorization, social identity, and social comparison. In H. Tajfel (Ed.), Differentiation between social groups: Studies in the social psychology of intergroup relations (pp.61-76). London: Academic Press.

Tajfel, H., \& Turner, J.C. (1979). An integrative theory of intergroup conflict. In W.G. Austin \& S. Worchel (Eds.), The social psychology of intergroup relations (pp. 33-47). Monterey, CA: Brooks/Cole.

Tajfel, H., \& Turner, J.C. (1986). The social of identity theory of intergroup behaviour. In S. Worchel \& W.G. Austin (Eds.), Psychology of intergroup relations (pp. 7-24). Chicago, IL: Nelson.

Thomas, R. R. (1990). From affirmative action to affirming diversity. Harvard Business Review, March-April Issue. Retrieved from https://hbr.org/1990/03/fromaffirmative-action-to-affirming-diversity

Turner, J.C., Hogg, M.A., Oakes, P.J., Reicher, S.D., \& Wetherell, M.S. (1987). Rediscovering the social group. Oxford: Blackwell.

U.S. Census Bureau. (2015). Projections of the size and composition of the U.S. population. Retrieved from https://www.census.gov/content/dam/Census/library/ publications/2015/demo/p25-1143.pdf

U.S. Department of Homeland Security. (2017). H-1B trends: 2007-2017. Retrieved from https://www.uscis.gov/news/uscis-makes-additional-data-employmentbased-visa-programs-available-support-hire-american-executive-order 
U.S. Department of Labor. (2017). Women in the labor force. Retrieved from https://www.dol.gov/wb/stats/NEWSTATS/facts/women_lf.htm\#one

van Dick, R. (2001). Identification in organizational contexts: Linking theory and research from social and organizational psychology. International Journal of Management Reviews, 3, 265. doi: 10.1111/1468-2370.00068

Ward, G. (2012). An investigation of performance and participation in employee resource groups at a global technology company (Doctoral dissertation). Retrieved from Wayne State University Digital Commons, (714).

Welbourne, T., \& McLaughlin, L. (2013). Making the business case for employee resource groups. Employment Relations Today, 40, 35-44. doi: 10.1002/ert.21409

Welbourne, T. M., Rolf, S., \& Schlachter, S. (2015). Employee resource groups: An introduction, review and research agenda. Academy of Management Proceedings, 1, 1-32, doi: 10.5465/AMBPP.2015.15661abstract

Welbourne, T. M., Rolf, S., \& Schlachter, S. (2017). The case for employee resource groups: A review and social identity theory-based research agenda. Personnel Review, 46, 1816-1834. doi: 10.1108/PR-01-2016-0004

Welbourne, T.M., \& Ziskin, I. (2012, October). Employee resource groups as sources of innovation [Webinar]. Retrieved from https://ceo.usc.edu/files/2016/01/ ERG_webinar_web.pdf

Wheeler, A. R., Harris, K. J., \& Sablynski, C. J. (2012). How do employees invest abundant resources? The mediating role of work effort in the jobembeddedness/job-performance relationship. Journal of Applied Social Psychology, 42, E244-E266. doi:10.1111/j.1559-1816.2012.01023.x

Yao, X., Lee, T. W., Mitchell, T. R., Burton, J. P., \& Sablynski, C. S. (2004). Job embeddedness: Current research and future directions. In R. Griffeth \& P. Hom (Eds.), Understanding employee retention and turn-over, 153-187. Greenwich, CT: Information Age.

Zhang, M., Fried, D. D., \& Griffeth, R. W. (2012). A review of job embeddedness: Conceptual, measurement issues, and directions for future research. Human Resources Management Review, 22, 220-213. doi:10.1016/j.hrmr.2012.02.004 


\section{Appendix}

\section{Survey Items:}

Job Embeddedness

Crossley, C. D., Bennett, R. J., Jex, S. M., \& Burnfield, J. L. (2007).

1. I feel attached to this organization.

2. It would be difficult for me to leave this organization. I'm too caught up in this organization to leave.

3. I feel tied to this organization.

4. I simply could not leave the organization that I work for.

5. It would be easy for me to leave this organization (reverse scored).

6. I am tightly connected to this organization.

\section{Organizational Commitment}

Meyer, J. P., \& Allen, N. J. (1991).

1. I would be very happy to spend the rest of my career with this organization.

2. I enjoy discussing my organization with people outside it.

3. I really feel as if this organization's problems are my own.

4. I think that I could easily become as attached to another organization as I am to this one.

5. I do not feel like 'part of the family' at my organization.

6. I do not feel 'emotionally attached' to this organization. 
Demographic Questions:

Gender identity, professional work experience, membership in ERGs, and frequency of participation in ERGs. 